
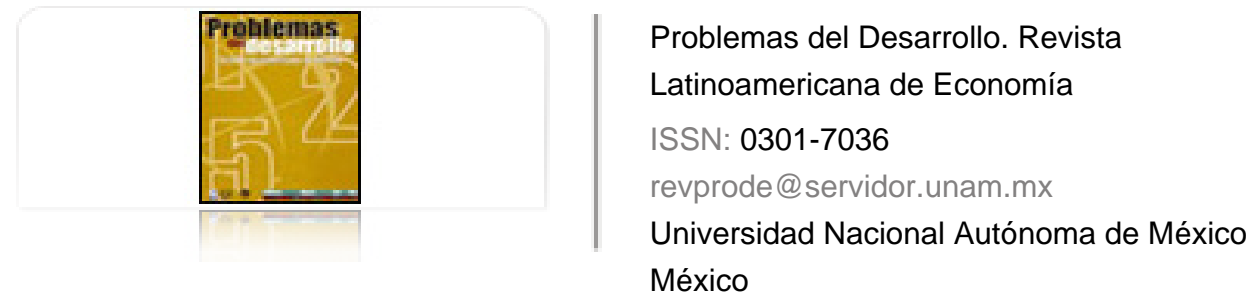

Figueroa, Víctor Manuel

América Latina: descomposición y persistencia de lo campesino

Problemas del Desarrollo. Revista Latinoamericana de Economía, vol. 36, núm. 142, julio-septiembre, 2005, pp. 27-50

Universidad Nacional Autónoma de México

Distrito Federal, México

Disponible en: http://www.redalyc.org/articulo.oa?id=11820079003

Cómo citar el artículo

Número completo

- Más información del artículo

Página de la revista en redalyc.org

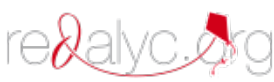

Sistema de Información Científica

Red de Revistas Científicas de América Latina, el Caribe, España y Portugal Proyecto académico sin fines de lucro, desarrollado bajo la iniciativa de acceso abierto 


\section{AMÉRICA LATINA: DESCOMPOSICIÓN Y PERSISTENCIA DE LO CAMPESINO}

\section{Víctor Manuel Figueroa*}

Fecha de recepción: 1 de abril de 2004. Fecha de aceptación: 30 de agosto de 2005.

\section{Resumen}

El debate económico y político en el marco de las crecientes preocupaciones que los problemas del agro latinoamericano vienen generando han llevado a un nuevo relevo en las perspectivas de una nueva economía campesina. Con el presente trabajo intentamos contribuir a esa discusión, para lo cual se emprende las siguientes tareas: a) dilucidar el concepto de lo campesino y sus relaciones económicas con el medio capitalista; b) definir las tendencias que apuntan a la transmutación social de la economía campesina, y c) determinar el papel de las politicas neoliberales en los deslizamientos en la estructura social del campo, en particular, la desarticulación y persistencia del mundo campesino.

Palabras clave: campesino, sobrepoblación ampliada, descomposición de la economía campesina, sobrepoblación absoluta, campesinización por ruina de capitalistas.

\section{Abstract}

The outlook for the campesino economy is recovering its place as a matter for economic and political debate within the framework of growing concerns about the problems of the Latin American farming sector. This study aims to contribute to that debate, and therefore tackles the following tasks: a) elucidate the concept of campesino and the economic relationship between this and the capitalist environment; b) define the trends aimed at the social transmutation of the campesino economy, and c) determine the role of neoliberal policies in the slippages in social structure in the countryside, in particular on the fragmentation and persistence of the campesino world.

Keywords: campesino, expanded over-population, decomposition of the campesino economy, absolute over-population, campesinization due to capitalist ruination.

* Unidad de Posgrado en Ciencia Política, Universidad Autónoma de Zacatecas. Correo electrónico: vmfig2000@yahoo.com.mx 


\section{VÍCTOR MANUEL FIGUEROA}

\section{Résumé}

Les perspectives de l'économie paysanne sont en train de récupérer leur place somme objet de débat économique et politique dans le cadre des préoccupations croissantes que génèrent les problèmes de l'agriculture latino-américaine. Le but de ce travail est de contribuer à cette discussion, raison pour laquelle on met en place les tâches suivantes: a) élucider le concept de ce qui est paysan ainsi que ces relations économiques avec le milieu capitaliste; b) définir les tendances qui pointent vers la transmutation sociale de l'économie paysanne, c) déterminer le rôle des politiques néolibérales dans les glissements dans la structure sociale du champ, en particulier sur la désarticulation et la persistance du monde paysan.

Mots clés: paysan, surpopulation amplifiée, décomposition de l'économie paysanne, surpopulation absolue, paysannisation à cause de la banqueroute des capitalistes.

\section{Resumo}

As perspectivas da economia campestre estão recuperando o seu lugar como tópico de debate económico e político no marco das crescentes preocupações que os problemas do campo da América Latina vêm gerando. Com o presente trabalho tentamos contribuir nessa discussão. Para tal fim se começam as seguintes tarefas: a) explicar o conceito do campestre e suas relações económicas com o médio capitalista; b) definir as tendências que assinalam à transmudação social da economia campestre e c) determinar o papel das políticas neoliberais nos deslizamentos na estrutura social do campo, particularmente, sobre a desarticulação e persistência do mundo campestre.

Palavras chave: campestre, sobre-população ampliada, descomposição da economia campestre, sobre-população absoluta, campestrinização por ruína de capitalistas. 


\section{Introducción}

a reforma agraria ha reaparecido en la reflexión y la práctica político-social latinoamericana. Su promoción cuenta con el Foro Mundial de la Reforma Agraria (FMRA), cuyo activismo se fundamenta en una circunstancia social en el nivel global que requiere atención: $a$ ) los objetivos de reducción de la pobreza no se cumplen, y $b$ ) la situación alimentaria en el mundo empeora. Dos mil millones de personas sufren malnutrición y cerca de 840 millones padecen hambre. Razones fuertes, considera el FMRA, para abordar la cuestión de la tierra y "situarla en la agenda prioritaria de los movimientos sociales rurales". ${ }^{1}$ Simultáneamente, los procesos de reforma agraria están siendo reactivados como programas de gobierno en Venezuela y Brasil, para dar respuesta a problemas sociales. Dichos procesos implican un nuevo impulso a la producción campesina, con lo cual pareciera desmentir toda la argumentación sobre su fracaso, al tiempo que demanda mayor atención a los aspectos políticos a la hora de explicar su "resistencia a desaparecer". Es oportuno, pues, revisar el devenir de la economía campesina, con el objeto de evaluar sus verdaderas posibilidades como solución a los problemas sociales y políticos de la actualidad.

El pequeño productor parcelario, en el contexto del capitalismo subdesarrollado, es una de las formas más conspicuas de la sobrepoblación ampliada ${ }^{2}$ en el campo. Su presencia está parcialmente inscrita en la lógica de crecimiento del capital y satisface una necesidad de la misma sólo en determinadas condiciones. La paz social, que ha movido a los gobiernos a promover oleadas de campesinización, es la causa principal de la existencia de los trabajadores del campo, sin desconocer otros orígenes en la historia, aunque también hay casos en los cuales han sido mantenidos a raya por largos periodos, sin grandes riesgos para el sistema. ${ }^{3}$ Mucho del devenir campesino se explica por la política: ésta puede reactivarlo, prolongar su existencia o acelerar su descomposición, pero no puede alterar sus tendencias económicas básicas.

http://www.fmra.org/.memoria.fmra.pdf.

2 La acumulación en nuestros países crea una sobrepoblación la cual es mayor que la población rela tivamente redundante para las necesidades del capital. Parte de ella, por tanto, no existe como resultado de las necesidades de la acumulación y para responder a ésta, pues surge más allá de estas necesidades. Por ello, aparece como sobrepoblación consolidada, absoluta, y se expresa en una existencia económica que se desenvuelve sin contacto con el capital (Figueroa, 1986).

3 Así ha sido, por ejemplo, en Bolivia, Venezuela y Colombia, países en los cuales la represión y las masacres rurales han llegado a ser tan despiadadas, que hasta se puede pensar que el aniquilamiento también ha constituido una forma específica de reacción a la sobrepoblación.

\section{Desaarrollo}


La pequeña producción parcelaria constituye uno más de los mecanismos por los cuales la sobrepoblación busca proveerse de medios de vida por canales alternativos a la producción capitalista. Parte de estos productores mantienen vínculos con la acumulación capitalista y se desenvuelven como sobrepoblación relativa; otros, cuentan entre la población absolutamente redundante respecto de los requerimientos de la valorización del capital. Dicha acumulación los produce como sobrepoblación y aun en los casos en los cuales creen haber hallado una fórmula más o menos segura para dotarse de medios de vida, ellos terminan encontrándose con que la misma acumulación destruye sus expectativas. Es decir, su existencia está sujeta a desplazamientos de un polo de la sobrepoblación a otro, a transmutaciones sociales que hacen de productores subsidiarios, ${ }^{4}$ pequeños productores independientes, la mayoría de los cuales, aún en edad de trabajar, deben apoyarse en familiares para su subsistencia. En un medio ambiente que los hostiliza constantemente, son forzados a luchar para obtener, mediante la política, el reconocimiento que la economía les niega. En la época de la globalización, se ha puesto en evidencia que la producción campesina no está determinada sólo por su lógica, tal como se despliega en el contexto del mercado capitalista y éste la condiciona. Sucesos paralelos aportaron nuevos bríos a la debilitada producción campesina; la globalización, en efecto, ha acelerado su descomposición al tiempo que contribuye a redefinirla para prolongar su presencia en el campo latinoamericano.

En el curso del presente trabajo nos proponemos discutir: $a$ ) el carácter social de la producción parcelaria, desde la perspectiva de su organización interna, esto es, la relación entre el productor directo y los medios de producción y el objetivo de su trabajo; $b$ ) sus relaciones con la acumulación capitalista; $c$ ) la dialéctica de la producción parcelaria en el marco de esas relaciones, y $d$ ) la transmutación social que esta dinámica contiene. Intentaremos lograr estos objetivos desde la perspectiva del análisis lógico, enfatizando el hecho de que las tendencias de la producción campesina operan independientemente de la orientación del crecimiento en cada periodo histórico pero, con el fin de acercarnos a la situación actual, buscaremos finalmente, $e$ ) detectar el impacto social de las políticas neoliberales, siguiendo los derroteros sugeridos por las elaboraciones precedentes. Abordaremos estos temas desde la perspectiva de la economía política y, por falta de espacio, prescindiremos, hasta donde nos parezca conveniente, de referencias directas a otras escuelas, que pudieran suscitar debates. Nos concentraremos en determinaciones generales, las cuales operan independientemente de la heterogeneidad de los espacios campesinos, pero que, desde diferentes formas, ritmos y formas concretas, están presentes en todos ellos.

4 Es decir, aquellos productores que llevan a cabo una función necesaria para la sociedad capitalista, aun cuando la organización interna de su trabajo no es la de ese modo de producción.

\section{Desarrollo}




\section{El carácter no capitalista de la economía campesina}

Siguiendo a F. Engels, diremos, en principio, que: "Por pequeño campesino entendemos aquí al propietario o arrendatario — principalmente al primero - de un pedazo de tierra no mayor del que puede cultivar, por regla general, con su propia familia, ni menor del que puede sustentar a ésta" (Marx y Engels, s/f:658).

No atenderemos a la sugerencia, implícita en esta cita de Engels, de que pueden existir campesinos grandes y medianos, y asumiremos que, al lado del productor campesino, sólo existen grandes, medianos o pequeños productores capitalistas, los cuales acumulan capital gracias a la explotación de trabajo ajeno. El campesino, por tanto, será un pequeño productor que: $a$ ) explota una extensión suficiente para su reproducción y la de su familia, y $b$ ) se vale, por regla general, de su fuerza de trabajo y la de su familia, pero puede recurrir al trabajo ajeno para las tareas donde el esfuerzo familiar es insuficiente.

La cuestión del modo de producción del campesino es inevitable. La noción de que estas cuestiones fueron resueltas en otro tiempo o la irresponsable apreciación de que en todo caso se trata de temas del pasado, no tienen otro efecto que eludir el enfrentamiento con una cuestión decisiva: no se puede clarificar el papel del campesino ni su lugar en la sociedad ni mucho menos su evolución misma, sin atender este problema. Pero, además, es una cuestión que cae dentro de la definición misma del campesino, por lo cual el concepto queda incompleto, sin resolverse.

Adoptaremos aquí el punto de vista de Marx, según el cual la agricultura campesina constituía un modo de producción distinto del capitalista, por lo cual quedaba excluida del análisis de este último en su forma pura. Esto puede apreciarse en el siguiente pasaje, que discute los supuestos para el análisis de la renta capitalista:

La forma de propiedad de la tierra que consideramos es una forma específicamente histórica de la misma, la forma trasmutada, por influencia del capital y del modo capitalista de producción, tanto de la propiedad feudal de la tierra como de la agricultura pequeño campesina practicada como ramo de la alimentación, en la cual la posesión de la tierra aparece como una de las condiciones de producción para el productor directo, y su propiedad de la tierra como la condición más ventajosa, como condición para el florecimiento de $s u$ modo de producción. Así como el modo capitalista de producción presupone, en general, que se expropie a los trabajadores las condiciones de trabajo, así presupone en la agricultura que a los trabajadores rurales se les expropie la tierra y se los subordine a un capitalista que explota la agricultura con vistas a la ganancia (Marx, 1986, vol. 8:791-792).

El trabajo campesino configura, pues, un modo específico de producción en el cual a las características antes anotadas (producción para el consumo y trabajo principalmente familiar), se agrega el control (implícito tanto en la posesión, como en la propiedad) sobre la tierra que trabaja.

Pocas cosas son unánimes en la ciencia social y este enfoque no es una de ellas. De ahí que resulte conveniente agregar algunas consideraciones.

\section{Desaarrollo}


a) En la definición del capitalismo, el objetivo de la producción, esto es, la producción de plusvalor, juega un papel fundamental. La compra de fuerza de trabajo sigue este propósito fundamental. En efecto, la fuerza de trabajo, decía Marx,

[...] no se compra aquí para satisfacer mediante sus servicios o su producto, las necesidades personales del comprador. El objetivo perseguido por éste es la valorización de su capital, la producción de mercancías que contengan más trabajo que el pagado por él, o sea una parte de valor que nada le cuesta al comprador y que sin embargo se realiza mediante la venta de las mercancías. La producción de plusvalor, el fabricar un excedente, es la ley absoluta de este modo de producción (Marx, 1986, vol. 3:767).

De modo que hablar de capitalistas, al margen de este rasgo crucial, es despojar a este modo de producción de su motivo esencial. El capitalista es tal porque utiliza trabajo ajeno con vistas a obtener una ganancia, la cual no es otra cosa que la forma trasmutada del plusvalor.

b) No toda contratación de trabajo ajeno tiene por objeto el plusvalor. Para que ello ocurra, en el plano de la producción, es necesario que el número de trabajadores contratados sea suficiente. No cualquier número de trabajadores o de jornadas transforman la producción en proceso de valorización. Es lo que sostiene Marx:

Lo que distingue desde un principio al proceso de trabajo subsumido aunque sea formalmente en el capital -y por lo que va distinguiéndose cada vez más, incluso sobre la base de la vieja modalidad laboral tradicional- es la escala en que se efectúa; vale decir, por un lado la amplitud de los medios de producción adelantados, y por otro la amplitud de los obreros dirigidos por el mismo patrón (employer). Lo que — a título de ejemplo— sobre la base del modo de producción corporativo aparece como máximo (con respecto, supongamos, al número de oficiales), puede apenas constituir un mínimo para la relación capitalista. Esa relación, en efecto, puede resultar puramente nominal allí donde el capitalista no ocupa por lo menos tantos obreros como para que la plusvalía producida por ellos le alcance como renta para su consumo privado y como fondo de acumulación, de tal suerte que quede él libre del trabajo directo y sólo trabaje como capitalista, como supervisor y director del proceso: por así decirlo, que ejerza la función, dotada de voluntad y conciencia, del capital empeñado en su proceso de valorización (Marx, 1985:57).

Lo cual tiene una implicación adicional que conviene explicitar: el objetivo de la producción no está determinado por la voluntad del productor, sino por las condiciones materiales en las cuales se desenvuelve. De nada le sirve a un empresario aspirar a una ganancia cuando sólo cuenta con medios para proveerse su subsistencia. Cuando el plusvalor pasa a ser para éste su objetivo y al mismo tiempo su resultado fundamental, entonces se ha producido una transformación cualitativa que hace de él un pequeño capitalista, lo cual es el resultado de los cambios cuantitativos que han tenido lugar en su proceso de producción.

c) La noción de "capitalista nominal" pareciera crear confusiones. No se refiere a una suerte de capitalista parcial. En otro pasaje de la obra de Marx adquiere claramente su 
contenido, esto es, una relación a la cual se le ha asignado un nombre que no merece y que en realidad corresponde a esferas distintas de la explotación capitalista.

Cuando el pequeño capitalista, quien hace todo el trabajo por sí mismo, parece obtener una tasa elevada de ganancia en proporción a su capital, lo que pasa en realidad es que, si no emplea unos pocos trabajadores de cuyo trabajo excedente se apropia, en los hechos él no obtiene ganancia alguna y su empresa es sólo nominalmente capitalista [...] Lo que lo distingue del trabajador asalariado es que, debido a su capital nominal, es dueño y director de sus propias condiciones de trabajo y por consiguiente no tiene un director sobre él; por lo tanto, se apropia él mismo de todo su tiempo de trabajo en vez de serle apropiado por alguien más. Lo que aparenta ser ganancia aquí, es meramente el excedente (de su ingreso) por sobre el salario ordinario, excedente que resulta del hecho de que se apropia de su propio sobretrabajo. Sin embargo, este fenómeno pertenece exclusivamente a aquellas esferas que no han sido todavía realmente conquistadas por el modo capitalista de producción (Marx, 1972:357).

De modo que el capitalista nominal no es, en realidad, un capitalista ni pequeño ni grande.

d) El campesino, que por lo general cultiva su parcela junto con su familia, también recurre al apoyo de otros para la ejecución de ciertas tareas. Ello le permite completar el trabajo con vistas a la reproducción. Éste hace posible que el recurso al trabajo ajeno adquiera formas distintas del trabajo asalariado. Allí donde las prácticas comunitarias no han sido aún disueltas por la mercantilización de las relaciones sociales, es posible encontrar mecanismos de cooperación entre los campesinos, consistentes, por ejemplo, en el intercambio de trabajo para la ejecución de determinadas tareas productivas. Esencialmente se trata de la misma relación establecida por el campesino que, después de contratar fuerza de trabajo para las tareas de la cosecha, debe vender a otro la suya propia para resarcirse de los gastos en salarios. Ello no transforma a los campesinos en pequeños capitalistas que explotan recíprocamente su trabajo ni en proletarios que viven de su salario. Por lo demás, ésta no es una simple posibilidad teórica. Hubert Carton de Grammont ha encontrado que se trata de una práctica bastante difundida en América Latina:

En cuanto a la contratación de mano de obra, hay que señalar un último fenómeno: el de las unidades de producción campesinas que se ven obligadas a transformar sus tradicionales relaciones de ayuda mutua en relaciones salariales debido a la monetarización general de la economía. [...] En este caso, la contratación de los asalariados es muy peculiar: los mismos campesinos (o sus familiares) se contratan entre ellos mismos y no se mezclan con el resto de los asalariados que trabajan en empresas capitalistas (1992:51).

Hasta aquí sólo hemos demostrado que la organización interna de la producción campesina no es capitalista, lo cual es crucial para la comprensión de su dinámica, porque implica que de ella no puede esperarse la lógica de funcionamiento del proceso específico de la acumulación, como tampoco puede esperarse que esté sujeta a la lógica de la renta

\section{DeSaarrollo}


capitalista. Pero ello no significa que se desenvuelva sin contacto con las categorías de la producción mercantil. Valor, mercancía, trabajo socialmente necesario, mercado, precios e incluso ganancia (esta última tampoco es una categoría particular de la producción capitalista) son imprescindibles para la comprensión de la economía campesina y mediante ellas toma lugar el vínculo con el entorno mercantil. Las categorías propias del capitalismo (principalmente plusvalor, ganancia extraordinaria, precios de producción y de mercado, valor de la fuerza de trabajo) reaccionan, a su vez, sobre el desenvolvimiento del campo y hacen sentir su peso dominante, por lo cual la economía campesina reclama su intervención. Este nexo está ya establecido en el nivel de la producción misma. Por un lado, el trabajador de campo constituye una fuente de realización de ciertas mercancías capitalistas. Por otro, este tipo de producción puede estar incorporada a la valorización del capital, lo cual ocurre, por ejemplo, cuando por medio del comercio, sus productos y, por tanto, su trabajo, pasan a formar parte del ciclo de alguna producción capitalista, ya sea abaratando el capital variable o como capital constante o, más directamente, cuando el campesino lleva a cabo una producción por contrato con alguna empresa. Para la producción capitalista, este tipo de relaciones puede resultar rentable precisamente porque los precios del productor pueden no incorporar el excedente que en determinadas condiciones le correspondería. No cabe duda que, mientras éste fuera el caso, las reformas agrarias han tenido también una expectativa económica. Como ha señalado Carlos Mistral, era de esperar que tal proceso: "Junto con activar la oferta agrícola, abarata el precio de la fuerza de trabajo (aumentando la tasa de plusvalor), ahorra divisas y absorbe el creciente descontento campesino" (1974:25).

Esto debe ocurrir dentro de ciertas condiciones históricas que combinan el nivel de desarrollo tecnológico alcanzado y la extensión de la tierra en poder campesino. Pero hay también una condición estructural que prolonga en el tiempo las posibilidades de que la producción campesina preste un servicio a la producción capitalista: el hecho de que en la agricultura capitalista deba pagarse una renta, encarece los precios en este sector y en esa medida reduce las exigencias tecnológicas sobre el sector campesino.

Por tanto, nos encontramos nuevamente con uno de los tantos casos en los cuales la organización no capitalista de la producción aparece incorporada a la acumulación y sus agentes, como sobrepoblación relativa. Entran por ello, en la categoría de pequeños productores subsidiarios, al igual que ocurre en la ciudad, por ejemplo, con el taller familiar de mecánica para automóviles.

Empero, para los agentes involucrados en esta categoría, no se trata de un estado permanente, porque un rasgo de la producción campesina es precisamente carecer de estabilidad y está inmersa en un proceso que involucra determinadas trasmutaciones sociales de los agentes involucrados. Su funcionalidad económica, por tanto, tampoco será permanente y aunque no determina su existencia, el agotamiento de la misma vendrá a acelerar la desarticulación de la producción campesina. 


\section{De la producción campesina a la de infrasubsistencia}

El supuesto sobre el que se diseñan los programas de reforma agraria en la región es, normalmente de manera implícita, el postulado de Chayanov acerca de la existencia de un equilibrio entre la satisfacción de las necesidades de la familia campesina y la fatiga del trabajo de la misma. O, en otras palabras, con su trabajo, más o menos intenso, el campesino puede lograr la satisfacción de sus necesidades de consumo. Por eso, la distribución de tierras se hace con base en un cálculo de la extensión, el cual puede proveer medios de subsistencia al campesino, en determinadas condiciones de calidad del suelo y de su localización.

Si Chayanov ha inspirado algún esfuerzo de reforma agraria, no es su culpa. Para él no pasaron desapercibidas las observaciones que tanto el escrutinio de la crítica, como el de los desarrollos reales, presentaron a su concepto del modo de producción campesino (noción que, como hemos visto, fue expuesta primero por Marx y Engels). Las discusiones en Rusia, sus estudios acerca de la agricultura estadounidense y, por tanto, sus reflexiones acerca del progreso tecnológico, le condujeron a otra temática: proyectar lo que él veía como ventajas de la producción campesina en la nueva organización social para la agricultura en su país. Sus propuestas de cooperativas, en oposición a la estatización y socialización de la tierra, transformaban la economía campesina en otra cosa, máxime cuando introducía criterios de rentabilidad, por lo cual sus reflexiones transitaban naturalmente a otro plano, en el cual aparecen nuevos fenómenos y categorías. Él abandonó, hacia 19281929, la defensa de la economía campesina y cerró de ese modo el debate que sus conceptos habían creado.

La noción de la economía campesina construida por Chayanov no debe ser criticada por no haber tomado en cuenta una u otra categoría de la producción capitalista (las cuales, por lo demás, concebía plenamente articuladas entre sí). Él mismo sostenía que dichas categorías poco o nada podrían aportar a la comprensión del fenómeno. Incluso, su planteamiento de algunas de ellas es objetable. Por ejemplo, él pensaba que la existencia de un mercado de trabajo, el cual estaba ausente en su economía campesina, permitía establecer una relación estrecha entre la esclavitud y el capitalismo, sin considerar que la forma estrictamente capitalista del mercado laboral es el de la fuerza de trabajo. Pese a ello, nos parece que la crítica fundamental a su trabajo es otra: él no había tomado en cuenta la influencia del desarrollo capitalista sobre el devenir campesino. El supuesto desde el cual había organizado sus reflexiones era que los distintos sistemas podían coexistir y que el esfuerzo del intelectual debía orientarse a revelar la forma de dicha coexistencia (Chayanov, 1987; Kerblay, 1987).

En Marx, la economía campesina es un proceso o, más exactamente, un proceso de descomposición debido, precisamente, a sus relaciones con el medio capitalista. Su opinión era que:

\section{Desaarrollo}


el artesano o el campesino que produce con sus propios medios de producción se transformará gradualmente en un pequeño capitalista que también explota el trabajo de otros, o bien sufrirá la pérdida de sus medios de producción [...] y se transformará en trabajador asalariado. Esta es la tendencia en una sociedad en la cual predomina el modo capitalista de producción (Marx, 1972:409).

Aquí, la sostenida reproducción del campesino carece, pues, de perspectiva, pero no menos cierto es que, en el contexto de nuestros países, su transformación en pequeño capitalista o en obrero asalariado tampoco son desenlaces necesarios. Habremos de ver más adelante que son otras las figuras sociales alimentadas por la descomposición del campesino.

Marx detectó múltiples causas que corroen por doquier la débil constitución de la estructura campesina. Destacan la desaparición progresiva de la industria domiciliaria rural que la complementa, la usurpación de la propiedad comunal, el desarrollo de cultivos en gran escala y "las mejoras en la agricultura — que por una parte provocan un descenso en los precios de los productos agrícolas, mientras que por otra requieren mayores desembolsos y más abundantes condiciones objetivas de producción- también coadyuvan a ello, como ocurrió en Inglaterra durante la primera mitad del siglo xvIII" (Marx, 1986, vol. 8:1026-1027). Aun cuando no mediara ninguno de los otros factores, bastaría la inevitable acción de los dos últimos para determinar la tendencia de la producción campesina.

La subsistencia de la familia campesina no depende solamente de lo que ella sea capaz de producir. Está también vinculada a la realización de sus productos (o parte de ellos) en un mercado dominado por el capital y en el cual los precios de producción están permanentemente a la baja. De ahí que, para mantener determinado nivel de consumo debe incrementar constantemente su producto. No puede limitarse a la mera reposición año con año de los bienes consumidos en su proceso productivo, ya que está forzado a hacer crecer su productividad a fin de mantener constante la relación de sus costos con el precio regulador fijado en el sector capitalista. En otras palabras, su subsistencia continua exige la generación de un excedente (la ganancia campesina) para invertir ciclo tras ciclo.

Supongamos que lo obtiene y que es suficiente para incorporar los insumos químicos, biológicos y mecánicos que le permitan aumentar la productividad de su trabajo, como en la esfera capitalista; hagamos abstracción aquí de todas las desventajas vinculadas a la calidad y localización del suelo que generalmente afectan al campesino. Aun así, nos quedaría por delante un escollo insalvable: las economías de escala ligadas a la gran producción, las cuales actúan como factor coadyuvante de la reducción de costos y, por tanto, de precios. Esta situación se agrava en la medida en que la producción de los instrumentos de producción y los insumos están cada vez más orientados a las grandes explotaciones. Por ejemplo, poco gana un productor que cuenta con, digamos, 15 hectáreas al adquirir un tractor diseñado para la explotación de 60 hectáreas. Sus costos de producción aumentarán 
respecto del productor capitalista que puede darle al tractor un uso más intensivo. Algo similar ocurrirá con todos los insumos, cuyos precios en el mercado disminuyen en la medida en que se adquieren mayores cantidades o con la perforación de pozos con capacidad de riego para extensiones relativamente grandes. Es decir, aquí puede apreciarse que la pequeña producción campesina adolece de una impotencia congénita para seguir con éxito la evolución de la agricultura capitalista. El costo de sus medios de producción tiende a ser más elevado en cada unidad de producto.

Pero luego aparecen dificultades adicionales: a) los canales de distribución de los fertilizantes, generados predominantemente en los países desarrollados, "tienden a atender principalmente las necesidades de productores grandes y medianos que cultivan productos tales como café, banano, caña, algodón, etc." (CEPAL, 1984:56). b) Lo mismo ocurre con los herbicidas y los insecticidas, con el agravante de que la aplicación de éstos demanda el uso de tractor. $c$ ) Los insumos biológicos y químicos (op. cit.), presentan complementariedad, lo cual conlleva una dificultad adicional para su adquisición.

Por su parte, A. Schejtman hizo notar además que:

La necesidad de valorizar su recurso más abundante — la fuerza de trabajo- - [...] unida a la presencia general o local de términos de intercambio desfavorables para los productos campesinos en los intercambios mercantiles, conducen a una tendencia a la reducción al número indispensable de la compra de insumos y medios de producción. Esto da lugar a que la densidad de medios de producción por trabajador, o de insumos comprados por unidad de productos o por jornada sean generalmente muy inferiores a los de la agricultura empresarial o capitalista (1980:131).

No es raro, entonces, que se haya podido establecer una relación directa entre el uso de insumos (incluyendo los mecánicos) y el tamaño de las explotaciones (CEPAL, 1986).

Los rendimientos de la producción campesina tenderán, por tanto, a crecer mucho más lentamente que los del sector capitalista. No se trata, pues, de que la producción campesina no mejore, sino de que, cuando lo hace, su crecimiento es lento. Como resultado, sus ingresos tenderán a caer. La teoría del valor nos permite alcanzar esta conclusión. Supongamos la siguiente situación inicial, tomando como referencia la producción de trigo:

Cuadro 1

\begin{tabular}{cccc}
\hline $\begin{array}{c}\text { Tipo de } \\
\text { producción }\end{array}$ & $\begin{array}{c}\text { Rendimiento } \\
\text { por hectárea }(q q)\end{array}$ & $\begin{array}{c}\text { Precio por quintal } \\
\text { (dólares) }\end{array}$ & Valor del producto \\
\hline Capitalista & 21 & 10 & 210 \\
Campesina & 14 & 10 & 140 \\
\hline
\end{tabular}

Esta situación es, de por sí, altamente desigual en cuanto a los rendimientos y ya supone un proceso previo de deterioro de la relación en contra del campesino. Mientras 
los datos de producción corresponden a los procesos reales, ${ }^{5}$ los precios, obviamente, son una elección para fines de exposición. Como tal, esta situación constituye, al mismo tiempo, un punto de partida para el deterioro ulterior. En la producción capitalista se introducirán mejoras tecnológicas, cualquiera que sea su ritmo, las cuales, como resultado, elevarán los rendimientos. Supongamos que, después de un periodo, se generaliza un incremento equivalente a $25 \%$ en la producción por hectárea, o sea, la producción capitalista se eleva de 21 a 26 quintales, ignorando las fracciones. Como estos rendimientos resultaron de cambios en la productividad del trabajo, el valor del producto total no varía; sólo se modifica el del producto individual, esto es, de cada quintal. Si las condiciones de producción en el sector campesino se mantuvieron inalteradas, lo cual suponemos para facilitar la exposición, entonces tenemos:

Cuadro 2

\begin{tabular}{cccc}
\hline Tipo de producción & $\begin{array}{c}\text { Rendimiento por } \\
\text { hectárea }(q q)\end{array}$ & Precio por quintal & $\begin{array}{c}\text { Valor del } \\
\text { producto por hectárea }\end{array}$ \\
\hline Capitalista & 26 & 8.08 & 210 \\
Campesina & 14 & 8.08 & 113 \\
\hline
\end{tabular}

El precio de mercado aparece aquí fijado por la competencia capitalista que generalizó en su interior ciertas condiciones de producción. ${ }^{6}$ Pero mientras el producto de la economía campesina es necesario y satisface una demanda de la sociedad, puede ocurrir que la producción capitalista fije sus precios por sobre su valor, obteniendo de ese modo

5 Los datos relacionados con los distintos rendimientos corresponden a la situación existente en Chile hacia fines de los setenta, según Álvaro Rojas (1984). El mismo autor informa de las diferencias de rendimientos para otros productos, en los siguientes términos.

\begin{tabular}{ccc} 
Rendimientos por hectárea de los principales & productos campesinos \\
\hline Rubro & $\begin{array}{c}\text { Rendimientos qq/ha } \\
\text { agricultura no campesina }\end{array}$ & $\begin{array}{c}\text { Agricultura } \\
\text { campesina }\end{array}$ \\
\hline Trigo & 21.3 & 13.5 \\
Cebada & 26.1 & 15.0 \\
Arroz & 30.0 & 25.5 \\
Maíz & 52.0 & 28.0 \\
Frijoles & 11.0 & 9.1 \\
Garbanzo & 4.9 & 4.9 \\
Papas & 157.0 & 90.0 \\
\hline
\end{tabular}

Fuente: Rojas (1984:148).

$6 \quad$ En Chile, el trigo, como la mayoría de la producción campesina, retomó su tendencia a la baja después de 1975, una vez que la economía empezó a dejar atrás los efectos del periodo especial abierto por el gobierno de la Unidad Popular a principios de la década. Su precio era de 2240 pesos de enero de 1982 y cayó a 780 pesos en 1981 (ibid::158 159).

\section{Desarrrollo}


una sobreganancia. Es decir, mientras la competencia y las mejoras en la productividad empujan hacia abajo los precios de mercado, la presencia de la producción campesina debilita el dinamismo de este proceso. Esto será particularmente cierto en condiciones de economía cerrada y mucho más cuando el Estado interviene para fijar precios que garantizan cierto ingreso campesino. Sin embargo, ello no elimina la competencia capitalista ni, por lo mismo, la búsqueda de mejoras tecnológicas que aumenten los rendimientos. Otra digresión: no se puede ignorar que los cambios tecnológicos alteran la intensidad del trabajo y la aumentan, pero, especialmente en la agricultura, estos cambios en la intensidad van de la mano con la reducción de la cantidad de fuerza laboral a disposición del empresario, por lo cual las modificaciones en la masa nueva de valor es poco significativa.

Independientemente de su ritmo, la concentración de la introducción de tecnología y de los aumentos en la productividad agrícola afecta inevitablemente al sector campesino. La tendencia de largo plazo es inmutable: una hectárea va arrojando un producto cuya expresión en dinero se va reduciendo con los cambios tecnológicos en el sector capitalista. ${ }^{7}$ El trabajo invertido por el campesino puede ser el mismo, pero su expresión monetaria será menor. Ello se debe a que como no modificó sus rendimientos al mismo ritmo que el capitalista, una parte creciente de su trabajo no alcanzó reconocimiento como socialmente necesario. La parte de su esfuerzo que es tratada por la sociedad como trabajo inútil también tenderá a crecer. Enfrentado al resto de la sociedad, el valor individual de su producto cae demasiado lentamente o simplemente no se reduce, debido a que su producto global no crece con la rapidez requerida o, bien, no manifiesta aumento alguno. El poder de compra del producto de su parcela se reduce con cada ciclo, lo que él percibe como un encarecimiento de los bienes industriales o reducción de sus precios. No es que el campesino venda barato mientras los productos que compra se encarecen, sino que se ha modificado la relación de los tiempos de trabajo invertido en la producción de sus mercancías y las de los capitalistas. Ésta es la clave del intercambio desigual con el resto de la sociedad: una cantidad dada de trabajo es cambiada por una cantidad menor de trabajo.

Se ha sostenido que por medio del mercado se generan transferencias de valor por parte del campesino, de las cuales se beneficia, principalmente, el capital industrial (Bartra, 1987). Ya Calva respondió, con toda razón, que ése no podía ser el caso, puesto que se

$7 \quad$ En México, según el censo agrícola y ganadero de 1970, la producción de maíz en las unidades de hasta cinco hectáreas era de $901 \mathrm{~kg}$, y de más de $1100 \mathrm{~kg}$ en las unidades privadas de más de cinco hectáreas. Tales eran los rendimientos promedio para los ciclos de invierno y verano. El censo de 1991 arrojó los siguientes resultados: ciclo de verano: $1088 \mathrm{~kg}$ por hectárea en las unidades de hasta cinco hectáreas, contra $1357 \mathrm{~kg}$ en las unidades de más de cinco hectáreas; ciclo de invierno: $1165 \mathrm{~kg}$ y $1856 \mathrm{~kg}$, respectivamente. Estos datos no se refieren a realidades sociales significativas, pues éstas no están necesariamente definidas por la extensión de la tierra, pero son expresión de las desventajas de la pequeña producción. Según la CEPAL, "en 20 años el rendimiento promedio del grueso de la producción de maíz en los minifundios ha aumentado desde aproximadamente 1000 a $1090 \mathrm{~kg}$ por hectárea". O sea, prácticamente nada (CEPAL, 1997:28).

\section{Desaarrollo}


trataba de trabajo perdido que no creaba valor (Calva, 1988). Pero hay algo más en relación con esta situación. El capital industrial no tiene interés económico en una producción campesina de baja productividad, porque en la medida en que ella involucra bienes que entran de manera decisiva en la determinación del valor de la fuerza de trabajo, se presenta como obstáculo para la producción de plusvalor relativo y, por tanto, para el desarrollo del capital en general. ${ }^{8}$ Esta situación es fuente de conflictos entre los intereses capitalistas del campo y de la ciudad, y también entre los de la industria y de los campesinos, ya que mientras la producción agrícola cubra una parte del mercado y se trate del mismo producto, el agricultor capitalista no está forzado a reducir sus precios individuales con arreglo a la evolución de su productividad. Puede, como hemos señalado, fijarlos por sobre su precio de producción, de manera que el precio regulador de mercado no cae todo lo rápido que debiera. En la medida en que ello ocurre, el trabajo de los obreros de la agricultura capitalista aparece como trabajo potenciado, lo cual contribuye a incrementar la tasa de plusvalor en esta rama, al tiempo que relaja las presiones para la innovación tecnológica en la misma. Pero de este modo no se crea plusvalor para la clase de los capitalistas ni mucho menos para los industriales.

Para responder a su difícil situación, el campesino se ve forzado a intensificar su esfuerzo y a prolongar su jornada, con la perspectiva de compensar con más trabajo la deficiencia en productividad. Pero no puede intensificar su trabajo ni prolongar su jornada como quisiera; aparte de las limitaciones físicas de su propia fuerza laboral, se tiene que enfrentar a otros constreñimientos naturales, como el clima pero, sobre todo, a la reducida masa de medios y objetos de trabajo con la cual cuenta. De nada le sirve estar dispuesto a explotar diez hectáreas si sólo cuenta con cinco.

La situación del campesino se ve agravada en la práctica por la expoliación de que es objeto por parte del capital en sus distintas formas, mediante todos aquellos mecanismos que Warman detectó en sus estudios empíricos (1976), los que Bartra intentó elaborar con mayor rigor (1979). Pero estos factores no juegan un papel necesario en la determinación del devenir de la economía campesina. Lo apuran, pero no lo provocan; pueden ser eliminados, como en buena parte ocurrió por un tiempo en México, pero no salvarán a la economía campesina de su proceso de descomposición.

Mientras la agricultura capitalista es atrasada y poco extendida, y la economía nacional se encuentra protegida, la producción campesina puede cumplir cierta funcionalidad para el desarrollo del capital, mediante la provisión de bienes salarios y materias primas a precios relativamente bajos, que el campesino puede sobrellevar mientras tenga un excedente al cual renunciar. Ello puede, incluso, levantar entusiasmo por la expansión de la economía

8 Marx señalaba: “Además, lo correcto en los fisiócratas es su tesis de que en realidad, toda producción de plusvalor, y por ende también todo desarrollo del capital se basan, con arreglo a sus fundamentos naturales, en la productividad del trabajo agrícola" (Marx, 1986, vol. 8:999). 
campesina en el Estado, el cual primariamente ve en ello una forma de dar salida a conflictos potenciales o reales creados por la sobrepoblación que de otra manera no podría hacerse de medios de vida. ${ }^{9}$ Excepcionalmente, también éste es el momento en el cual algunos trabajadores del campo pueden transformarse en pequeños capitalistas. El avance de la agricultura empresarial erosiona esa funcionalidad hasta aniquilarla; para entonces, el horizonte del campesino se estrecha y se cubre de nubes que anuncian miseria e incertidumbre.

El desbaratamiento de la economía campesina, esto es, su agotamiento como proveedora de medios de subsistencia suficientes para la familia, va acompañada, pues, de la desarticulación de sus agentes como pequeños productores subsidiarios y la transmutación de su condición social. Su contacto con la acumulación capitalista no ha hecho otra cosa que empobrecerlo, por lo cual ya no le resulta funcional y tenderá, por consiguiente, a refugiarse en el autoconsumo, mientras conserva con aquélla vínculos más bien esporádicos. En lo fundamental, en adelante se desenvolverá como pequeño productor independiente. Este proceso afectará, en primer lugar, a aquellas unidades relativamente más pequeñas, con tierras de peor calidad, para luego extenderse hacia el resto. Se van sumando de este modo a aquellas pequeñas explotaciones que nunca llegaron a organizarse como economía campesina. Si tomamos, a modo de ilustración, la tipología que en la CEPAL se elaboró para el caso de México, diríamos que se trata de los productores de infrasubsistencia. En el nivel inmediatamente superior, nos encontraríamos con el eslabón inferior del estrato campesino propiamente, esto es, los de subsistencia, donde ya no se generan recursos para la reposición de los medios de producción una vez satisfechas las necesidades de alimentación. Más arriba estarían los campesinos estacionarios que se diferencian apenas de los anteriores porque generan un fondo de reposición, pero insuficiente. Finalmente, en el

9 La distribución de tierras en la región empieza a tener lugar en la fase temprana del desarrollo del capitalismo. En Paraguy, por ejemplo, el Estado dictó en 1926 una ley que explícitamente recogía la necesidad de distribuir tierras en cantidad suficiente para el sostenimiento del productor y su familia, es decir, reconocía la necesidad de organizar productivamente a aquella parte de la población que no podía ser absorbida por el capital, un reconocimiento que la revolución había impuesto en México años antes. En Panamá, este proceso de asentamiento en el campo tuvo motivos peculiares, pero reveladores. A. Gandásegui (hijo) describe el proceso en los siguientes términos: "Las gigantescas obras de la construcción del ferrocarril transatlántico, a cargo de una empresa estadounidense, del canal en el Istmo por los franceses y de la construcción del canal de Panamá, además de la expansión de la producción bananera de la provincia de Boca del Toro, promovieron la inmigración de una gran masa laboral. La sola construcción de dicho canal atrajo a más de cien mil trabajadores extranjeros. Concluidas las labores, una parte de dicha fuerza emigró, otra buscó refugio en las ciudades y "miles de trabajadores se desplazan al campo". Obreros cesantes se transformaban así en pequeños productores rurales. De ahí que para el autor "El campesino era prácticamente un proletariado refugiado en el campo" (1985). Pero, ¿qué otra cosa es el trabajador separado de los medios de producción que busca hacerse de una parcela porque no tiene acceso al trabajo asalariado? El hecho de que antes de hacerse de una parcela haya trabajado o no como asalariado no cambia en nada la esencia de las cosas.

\section{DeSaarrollo}


peldaño superior, tendríamos a los campesinos excedentarios, aquellos que cuentan con cierto nivel de inversión (CEPAL, 1986), el cual les permitirá conservar determinado consumo por algún tiempo. En estas categorías, la contratación de fuerza laboral no supera las 25 jornadas anuales. Siguiendo la interpretación del devenir de la economía campesina que hemos expuesto, los eslabones inferiores tenderán a ensancharse a costa de los superiores, de modo que habrá un número creciente de campesinos en situación de ser despojados de su calidad de tales y que, en los hechos, lo son. No se trata necesariamente de un desplazamiento sucesivo, peldaño por peldaño, hacia abajo. Procesos como una crisis pueden provocar desplazamientos bruscos que saquen violentamente, por ejemplo, a un estacionario de su mundo campesino. Lo mismo ocurre tras las subdivisiones de la parcela por herencia.

Cuando un productor entra en el nivel de la infrasubsistencia, o aun si está en la transición hacia ello como campesino de subsistencia, recibe el aviso de que no puede seguir postergando la búsqueda de otra ocupación. Al salir tras ella, se encuentra con que la salarización proletaria choca con las barreras ya conocidas. En un estudio acerca del mercado laboral en México, sobre la base de datos obtenidos en el segundo trimestre de 1988, se concluyó que:

De aquellos que se dedicaron a actividades agropecuarias, el $28.9 \%$ lo hizo por cuenta propia, el $13.1 \%$ como empleadores y el $58 \%$ restante fueron trabajadores subordinados, es decir, asalariados, peones o jornaleros que no disponen de tierras y laboran en parcelas ajenas, constituyendo una población de 3.644.732 habitantes. Sin embargo, de esta población trabajadora, encontraron empleo como asalariados permanentes sólo en $2.6 \%$ y el $21 \%$ como peones o jornaleros a destajo, es decir 1.495 .597 , lo que representaba el $9.5 \%$ de la PEA. Si a esta información agregamos que el $51.6 \%$ de ellos fueron contratados por ejidatarios o comuneros individuales, frente a un $12.3 \%$ que fueron contratados por agricultores y empresarios, y que el $34.1 \%$ del total de los "subordinados" no recibió ningún tipo de remuneración, se evidencia la poca capacidad de contratación de la fuerza de trabajo en actividades agropecuarias y lo limitado del mercado de trabajo propiamente rural (Lara Flores, 1992:43).

Las mismas causas que explican la economía campesina dificultan que sus desechos humanos ganen un lugar en la explotación capitalista. En ese sentido, los procesos específicos que acompañan el avance de la agricultura capitalista estrechan aun más las oportunidades. En efecto, PREALC hace ya tiempo que pudo apreciar en la agricultura capitalista latinoamericana: $a$ ) una disminución del trabajo permanente en beneficio de las contrataciones temporales, como resultado de la modernización de los medios y de la organización de la producción, y b) la eliminación de las relaciones tradicionales al interior de la propiedad latifundista donde se sostenían personajes como huasipungos, colones, arrendires e inquilinos, los cuales se suman así a la desbordante oferta de fuerza de trabajo (PREALC, 1982:25-26). Pero, por otro lado, en sentido estricto, la proletarización no es necesariamente el objetivo del trabajador, pues a menudo aspira a mantener sus lazos 
con la parcela. Quienes anhelan y logran contratarse como asalariados permanentes en el campo o en la ciudad serán, pues, los menos. Ellos han realizado su metamorfosis en proletarios con parcela. En la medida en que apenas alcanzan a complementar sus ingresos provenientes de la tierra con otras actividades, lo cual ocurrirá en la mayoría de los casos, son precarios productores independientes, arrojados fuera del circuito capitalista. Caen en la esfera de la sobrepoblación consolidada, absoluta, que la producción capitalista tiende constantemente a ampliar, incrementando la masa de desempleados sobre lo que, en otras condiciones sociales, sería la base material para el tiempo libre. La parcela ya no es el domicilio de la familia; sus integrantes emigran buscando fuentes alternativas de subsistencia y, a menudo, deben aportar al sostenimiento de quienes se quedan, normalmente trabajadores en el ocaso de su vida laboral.

La calificación de las generaciones desplazadas es generalmente la de jornaleros, y en esa calidad una parte de ellos sólo cambian de trabajo eventual. Otros se proletarizan en la ciudad, ya sea en la industria o en el comercio, pero la gran mayoría se incorpora directamente a la sobrepoblación relativa, en el pequeño y microcomercio o a la sobrepoblación absoluta en las ciudades en actividades por cuenta propia, como lavacoches, artesano independiente, vigilante voluntario que vive de la caridad de los vecinos, cargadores de equipaje o de aquellos que ingresan al estrato doméstico de esta categoría, trabajando para asalariados. No hay manera de medir ese desplazamiento de clases a partir de la información existente, pero una cosa es cierta: una gran parte de los integrantes de la familia no se proletariza, en cuanto a acceder al trabajo asalariado. De donde se sigue que la pequeña producción agrícola sólo cumple parcialmente la función de proveer fuerza de trabajo para la explotación capitalista, lo cual es comprensible en el contexto de un capitalismo que no sólo crea una sobrepoblación relativa, sino también una que es absolutamente redundante para sus necesidades de valorización.

Es cierto que la explotación de infrasubsistencia no es completamente inútil y el productor no escatimará esfuerzos para obtener de su parcela el máximo provecho. Los cultivos tienden a concentrarse en productos para el autoconsumo a fin de asegurarse ciertos bienes necesarios para su subsistencia, invirtiendo menos en producir alimentos que en adquirirlos. La parcela también le abre ciertas oportunidades para la crianza de aves o ganado menor; junto con ello su dieta se empobrece, pero ya no puede confiar en el mercado. Entre los pequeños productores del campo, la producción para el autoconsumo tiende a ensancharse. De este modo, la parcela provee una parte de los alimentos y un lugar dónde vivir, en especial a los padres y a los hijos menores. Pero la pequeña explotación ya no es sostenible por sí misma, lo cual hace decisiva la intervención de los integrantes de la familia que han encontrado otras ocupaciones que, con sus aportaciones, mantienen la parcela.

\section{Desaarrollo}


Hay, además, otro aspecto involucrado: si los miembros de la unidad lograran hacerse de una ocupación permanente y relativamente segura, sus lazos con la misma tenderían a debilitarse más prontamente. Sin embargo, sus empleos son frecuentemente precarios, estacionales y a menudo extralegales. Debido a ello, la parcela puede operar como un hogar de emergencia para los familiares cada vez que se ven lanzados al desempleo, lo cual contribuye a mantener vivos los vínculos con éste. Mientras tanto, los que permanecen en la parcela no tienen manera de ocultar su pertenencia a la sobrepoblación consolidada o absoluta, hacia la cual han sido empujados por la propia evolución capitalista, la misma que en otro momento consideró necesaria la expansión de los campesinos.

\section{Efectos sociales del neoliberalismo en el campo}

La globalización neoliberal vino a crear un contexto particularmente grave para la sobrepoblación en el campo. La forma del crecimiento orientada al exterior aceleró la descomposición de la economía campesina y estrechó de manera particularmente aguda el mercado laboral urbano, cerrando todavía más las perspectivas de los desocupados. Pero en el análisis que hemos realizado hasta ahora, se ha puesto de manifiesto que las tendencias que afectan a la producción campesina operan independientemente de la forma del crecimiento en vigencia.

La apertura comercial trajo consigo nuevas exigencias en términos de productividad, por lo cual otros sectores fueron expulsados de su mundo campesino hacia el ejército de infrasubsistencia. La importancia social de este sector es enorme, a pesar de lo cual sigue creciendo. Ya en 1970, los productores con una parcela, cuyo potencial era insuficiente para alimentar a la familia, constituían 55.6\% del total en México. Entonces, los productores de maíz y frijol en el nivel de la infrasubsistencia sumaban alrededor de 1.09 millones (CEPAL, 1986:118-119). A fines de los noventa se calculó que el número de productores de maíz y frijol que dejaron de cultivar con vistas al mercado alcanzaba ya la cifra de 1.4 millones (CEPAL, 1999). Para Centroamérica se estimó que el número de pequeños productores en microfincas y fincas subfamiliares creció de 1040.4 a 1140.5 entre 1989 y 1993, y se proyectó que llegarían a 1325.5 en 2000 (ibid.) Es aquí donde se localiza la mayor parte de la sobrepoblación rural y no en la economía campesina. Su forma principal es la de sobrepoblación consolidada y no relativa.

Esta evolución socioeconómica contiene graves implicaciones políticas. Es aquí también donde se acumula el potencial de lucha más radical en el campo. Ofrecer la vida a una causa parece ser más fácil cuando la existencia está siendo consumida por las enfermedades de la pobreza y se carece de expectativas. Es simplemente lógico que la revolución en Nicaragua o la guerrilla en El Salvador hayan reclutado de este sector la mayor parte de su fuerza social y política o que en México ocurra otro tanto con la guerrilla zapatista. Si en algún momento la pequeña producción parcelaria representó una válvula de escape para los 
conflictos sociales, hoy día parece claro que, tratándose de una solución que no atacaba los problemas de fondo, sólo podía operar parcial y provisionalmente.

La conclusión de todo lo anterior, en relación con el destino de la producción campesina, parece no presentar resistencias: la economía campesina latinoamericana está condenada a desaparecer y en la actualidad está acelerando su descomposición. Pese a todo, sin embargo, esta conclusión no sería totalmente correcta: la presencia de la economía campesina no depende sólo de las posibilidades que ella misma contiene.

Los procesos que tienen impacto en los pequeños productores del campo no se reducen a la dinámica específica de la producción campesina y de infrasubsistencia. Según se percibe en el caso de México, en el seno de la agricultura capitalista está teniendo lugar un desarrollo que viene agravando su deteriorada situación, pero que también está dejando su marca entre los sectores más débiles de la propia producción empresarial. La reorientación del crecimiento, situando como eje al mercado externo, por un lado, redujo los estímulos a la producción en la medida en que contrajo el mercado local. Esta contracción aparecía en un principio como una condición para hacer posible la conversión de la producción y el desplazamiento de los capitales hacia la generación de bienes para la exportación. Luego, una demanda interna reducida devino en factor inherente al esquema de crecimiento, en la medida en que éste envilecía al trabajo y concentraba drásticamente el ingreso. El funcionamiento económico internalizó elevados niveles de desempleo, un crecimiento del PIB por persona muy inferior al del periodo de crecimiento orientado al mercado interno (más de 3\% entre 1945-1980 contra 1.6 entre 1990-2000), más altos niveles de pobreza. Por otro lado, los precios internacionales de los productos agropecuarios, a los cuales habría de sujetarse la región en el marco de la apertura, continuaron su tendencia de largo plazo a la baja.

Esta evolución de los precios informaba de los cambios en la productividad y, por tanto, reflejaba el tipo de desafíos a que eran llamados los productores latinoamericanos en cuanto a la introducción de progreso tecnológico. Pero, en los hechos, la apertura comercial venía a poner a la agricultura y a la producción pecuaria frente al desafío de competir con capitales que producen en mejores condiciones y que controlan el progreso tecnológico o simplemente tienen acceso más fácil al mismo. De este modo, la agricultura capitalista local fue situada, respecto de la producción de los países desarrollados, en una posición de desventaja similar a la que son empujados los campesinos frente a ella. En efecto, y a manera de ejemplo, la comparación de la productividad entre América Latina y Europa, Estados Unidos, y Canadá arrojaba entre 1970 y 1990 interesantes resultados (véase Cuadro 4).

Detrás de estas diferencias hay un uso muy dispar de insumos y una distancia que no cede significativamente. En 1979, por ejemplo, para ocho países desarrollados (Canadá, Estados Unidos, Bélgica, Noruega, Francia, Suecia, Reino Unido e Italia) se observó un

\section{Desaarrollo}


VÍCTOR MANUEL FIGUEROA

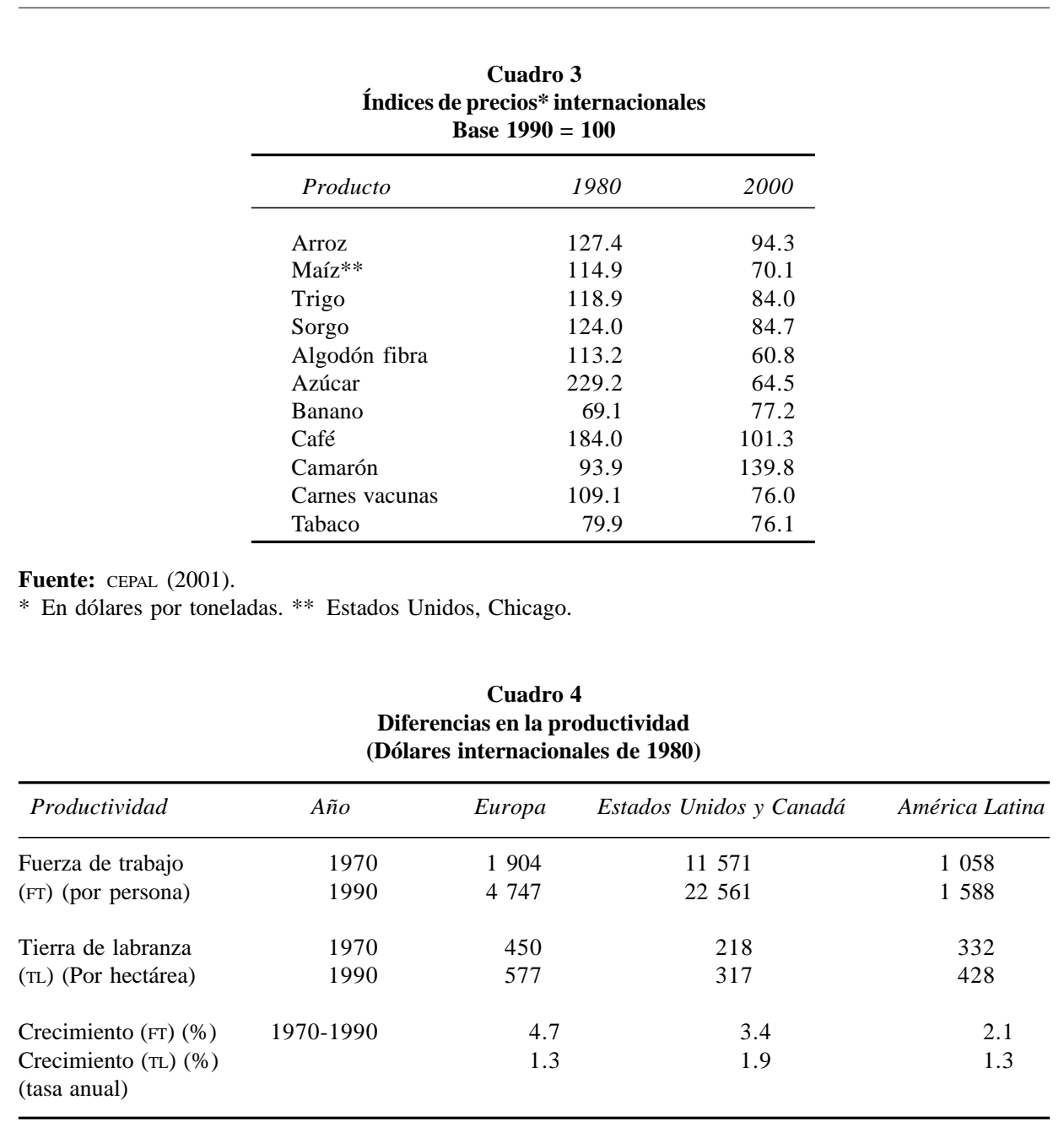

Fuente: CEPAL (1995).

uso de 6.28 tractores por cada 100 trabajadores en promedio en 1970. En 1990, en número de tractores había aumentado a 13.24. En diez países latinoamericanos (Uruguay, Argentina, Venezuela, Chile, Brasil, Costa Rica, México, Paraguay, Colombia y Guatemala), el número de tractores que se usaba en 1970 era de 0.39 por cada 100 trabajadores (o 3.90 por cada mil), cifra que aumentó apenas a 0.69 veinte años después. Lo mismo ocurre con los fertilizantes. En el primer grupo de países se empleó en promedio $120.6 \mathrm{~kg}$ de fertilizantes por hectárea en 1970 y $136.0 \mathrm{~kg}$ en 1990 . En el mismo grupo de países de la región se consumieron 6.97 y 16.85 en los años indicados (CEPAL, 1995).

Como cabía esperar, esta evolución de la productividad debía confirmar la tendencia histórica a la caída en la contribución de la región en los mercados internacionales y así 
fue. La participación latinoamericana en las compras agropecuarias de la OCDE disminuyó de $14.50 \%$ en 1980 a $11.20 \%$ en 1993 (ibid.), deslizamiento que continuó para alcanzar el $6 \%$ a fines de la década de los noventa (CEPAL, 2001b). Así, se puede apreciar que la baja ha sido más pronunciada cuanto más consolidado estaba el esquema. Esta pérdida de competitividad pone de manifiesto la insuficiencia de las mejoras que efectivamente tuvieron lugar durante los noventa con vistas a elevar los rendimientos. La contribución de la producción agropecuaria a la balanza comercial perdió peso, pues a pesar de que algunos países mantuvieron durante los noventa comercio internacional con saldo positivo, la importancia relativa de éste tendió a caer. En el contexto de una apertura comercial en la cual la agricultura ve reducida su participación en el comercio, la balanza agroalimentaria de algunos países se vio desde muy temprano gravemente dañada. ${ }^{10}$

Pero no menos significativas son las repercusiones sociales internas de esta situación. En principio, ello debiera traducirse en empobrecimiento de los productores medios y pequeños orientados al mercado interno pero, en el fondo de las cosas, nos encontramos con varios tipos de desarrollo mucho más complejos. Se trata, en realidad, de una evolución que se traduce en deslizamientos sociales hacia abajo, los cuales vienen a engrosar las filas de la producción campesina, como si ésta necesitara compensar, aunque sólo fuera débilmente, su propia descomposición. En efecto, porque si se observa con atención los detalles de este proceso se encontrará que su contenido es la campesinización de cierta masa de empresarios capitalistas.

A raíz de la evolución de los precios, se modificó la extensión de cultivo que permitía el sostenimiento de las familias, pero también el mínimo que concedía la obtención de una ganancia que hiciera viable la producción capitalista. La CEPAL constató esta situación para el caso de México en los siguientes términos:

La caída del ingreso en la producción de granos en el segmento tradicional de productores se ha reflejado en una tendencia hacia la concentración de la producción [...] Sólo produciendo en extensiones más grandes, los agricultores han podido mantener el nivel de ingresos que tenían a principios de los ochenta. Ello, por supuesto, ha implicado la salida de varios agricultores del mercado.

Algunos agricultores entrevistados señalan que, si anteriormente lograban un ingreso adecuado con 100 hectáreas sembradas de granos, ahora requieren producir en 250 hectáreas para más o menos mantener su nivel de ingresos. Así la producción de granos se ha convertido en una actividad de "volumen"; además ahora demanda una mayor capacidad

10 En el caso de México, la CEPAL ha señalado: "Después de haber sido una fuente neta de divisas, a partir de la segunda mitad de los ochenta el sector se volvió deficitario. Entre las importaciones más relevantes figuran los cereales, que en los últimos tres años han representado, en promedio, $23 \%$ del consumo (principalmente sorgo, seguido de trigo y en menor medida, maíz, cuya cosecha alcanzó niveles récord en los últimos ciclos), oleaginosas (semillas y pastas), aceites, carnes (de cerdo y aves en particular) y productos lácteos. Pese a ser un exportador neto de frutas y hortalizas, el valor de sus importaciones se triplicó entre 1990 y 1993" (CEPAL, 1995a:21).

\section{Desaarrollo}


de análisis por parte del agricultor sobre la mejor combinación de insumos a aplicar, dados los constantes cambios en sus precios relativos y, ante la contracción del crédito para el agro, el agricultor debe contar con el suficiente capital para financiar él mismo su actividad. Nuevamente, sólo un segmento relativamente reducido de productores cuenta con estas habilidades (CEPAL, 1999:74).

De este modo, cierta masa de capitalistas, la cual no estamos en condiciones de precisar numéricamente, fue empujada a la producción para la subsistencia. Las estadísticas apoyan esta aproximación, aunque no necesariamente la demuestran. Por un lado, en México cayó de manera dramática el número de empleadores de fuerza de trabajo: se estimaban en 855168 para 1988, al tanto que la encuesta nacional de empleo de abril-junio de 2000 sólo registró 166 557. Por otro, ha disminuido el número de trabajadores agropecuarios asegurados en el Instituto Mexicano de Seguridad Social en 21\% entre 1982 y 1998, mientras que ha crecido el número de trabajadores por cuenta propia de 1924854 a 2669 355, entre 1988 y 2000 (ibid. e INEGI, 2000).

En una investigación que tuvimos la oportunidad de conducir, llevada a cabo por Imelda Castro en Zacatecas, México, se pudo confirmar la sensatez de este postulado (Castro, 1996). Se constató la existencia de empresarios capitalistas que debieron reducir al mínimo el uso de fuerza de trabajo asalariada o abandonarlo completamente para hacer descansar la producción en el trabajo familiar, que desecharon el uso del tractor para reemplazarlo por la yunta, que transformaron tierras de riego en temporal por los altos costos de la electricidad, que han dejado de aspirar a una ganancia para concentrarse en el consumo, y que constituyen una realidad bastante difundida en el agro de este estado. Es cierto que en México ha habido condiciones especiales para la aceleración de estos desplazamientos de clase, ya que están de por medio no sólo las constantes recesiones, sino también una brutal ofensiva del capital bancario contra los productores, en particular los medianos y pequeños, la cual privó a éstos de crédito y los transformó en deudores de largo plazo. Pero la tendencia general de la economía ya apuntaba en ese sentido y no será fácil revertir esta situación mientras las condiciones generales del desenvolvimiento económico, esto es, el crecimiento orientado al exterior, persistan.

Políticamente, dichos desplazamientos sociales en el agro mexicano también han tenido su expresión específica, como en realidad cabía esperar. ${ }^{11}$ Del curso de los acontecimientos en el nivel político nada puede anticiparse, ni siquiera los juicios sobre su evolución.

11 El movimiento político de los productores del campo en México ha encontrado diversas expresiones correspondientes a las diferencias objetivas que existen entre ellos. Una expresión más adecuada a la producción de infrasubsistencia es el movimiento zapatista surgido en Chiapas. A su vez, los productores capitalistas pequeños y medianos que están siendo arrojados a la economía campesina encontraron su expresión orgánica más adecuada en El Barzón. La apertura de ciertas posibilidades para la resolución de los problemas financieros de estos últimos, dentro del esquema económico en práctica, por momentos logró contener sus luchas y debilitar la fuerza de la organización. En la actualidad, se despliegan esfuerzos por revitalizar el movimiento. 
De lo que no cabe duda es que el siglo xxI está iniciando con una nueva ola de acumulación de tensiones en el campo latinoamericano, la cual se arrastra desde las últimas décadas del siglo pasado y que se prolonga, agudizando cada vez más la necesidad de una respuesta.

\section{En conclusión}

El entorno capitalista agobia la economía campesina y la empuja a su desarticulación como recurso para garantizar la reproducción de la familia. Junto con ello, el campesino es desplazado de su condición en la escala social. La razón última de esta tendencia a la descomposición no se encuentra en una supuesta explotación del campesino por el entorno capitalista, ni siquiera en la expoliación del cual es objeto por el capital comercial, sino en su impotencia para seguir el ritmo de los cambios en la productividad. Sin embargo, el capitalismo subdesarrollado destruye la economía campesina y la reconstruye mediante la desarticulación de la empresa capitalista más débil y la expansión de una sobrepoblación cuyas demandas busca satisfacer a través de la distribución de tierras en pequeñas parcelas.

Las reformas agrarias orientadas a la creación de economías campesina, sin embargo, sólo pueden relajar tensiones sociales y políticas de manera provisional. Si en el pasado pudieron cumplir temporalmente una funcionalidad económica para el capitalismo, hoy día el desarrollo de las fuerzas productivas exige nuevas condiciones en cuanto a la extensión de la parcela y a la dotación de recursos tecnológicos. Ambos requisitos reducen la masa de población, cuyas demandas pueden ser atendidas. Y aun así, mientras la parcela se limite a satisfacer las demandas de consumo de las familias, la economía campesina será víctima de su propia dinámica. Parece claro, pues, que los gobiernos debieran concentrarse en la búsqueda de otras soluciones y, entre ellas, el impulso a la gran empresa agroindustrial, ya sea estatal o en la forma de cooperativas de productores directos, ofrecen, ciertamente mejores posibilidades de éxito.

\section{Bibliografía}

Bartra, Armando, La explotación del trabajo campesino por el capital, México, Editorial Nacional, 1979.

Bartra, Roger, Estructura agraria y clases sociales en México, México, Era-unam, 1987.

Calva, José Luis, Los campesinos y su devenir en las economías de mercado, México, Siglo xxi, 1988.

Carton de Grammont, Hubert, "Algunas reflexiones en torno al mercado de trabajo en el campo latinoamericano", en Revista Mexicana de
Sociología, año LIV/núm. 1, México, unam, enero-marzo de 1992, pp. 49-58.

Castro, Imelda, "Depresión económica y transformaciones sociales en la agricultura zacatecana", tesis de maestría en Ciencia Política, México, Universidad Autónoma de Zacatecas, 1996.

Chayanov, Alexander V., "Sobre la teoría de los sistemas económicos no capitalistas", en José Aricó (compilador), Chayanov y la teoría de la economía campesina, México, Ediciones Pasado y Presente, 1987.

\section{Desaarrollo}


Comisión Económica para América Latina (CEPAL), La agricultura campesina y el mercado de alimentos: La dependencia externa y sus efectos en una economía abierta, Santiago de Chile, Naciones Unidas, 1984.

Desarrollo Productivo núm. 43, Santiago de Chile, Naciones Unidas, 1997.

- núm. 57, Santiago de Chile, Naciones Unidas, 1999

Figueroa, Víctor M., Reinterpretando el subdesarrollo. Trabajo general, clase y fuerza productiva en América Latina, México, Siglo xxIUniversidad Autónoma de Zacatecas, 1986

Gandásegui, Marco A., 1985, "Historia política de las luchas campesinas en Panamá", en Pablo González Casanova (compilador), Historia Política de los campesinos latinoamericanos, México, unAm-Siglo XXI, 1985, pp. 181-220.

INEGI, Encuesta Nacional de Empleo (documento en línea): $h t t p: / / w w w . I N E G I . G O B . M E X, 2000$

Información básica del sector agropecuario. Subregión Norte de América Latina y el Caribe, 1980-2000, México, CEPAL, LC/MEX/L. 506, 2001.

Intercambio comercial agropecuario entre el Istmo Centroamericano y México: Situación actual y perspectivas México, CEPAL, LC/MEX/L.285, 1995a.

Lara Flores, Sara María, "La flexibilidad laboral del mercado de trabajo rural: una propuesta que involucra a las mujeres", Revista Mexicana de
Sociología, México, unAM, año LIV/núm. 1, enero-marzo de 1992, pp. 29-48.

Marx, K. y Engels, F., Obras Escogidas, Moscú, Progreso s/f.

Marx,Karl, Theories of Surplus Value (Part 1 y 3), Londres, Lawrence \& Wishart, 1972.

Mistral, Carlos, Chile: del triunfo popular al golpe fascista, México, Era, 1974.

Panorama de la agricultura de América Latina y el Caribe 1990-2000, Santiago de Chile, Naciones Unidas, 2001b.

Programa Regional para el Empleo en América Latina y el Caribe (PREALC), Medición del empleo y de los ingresos rurales, Santiago de Chile, Naciones Unidas, 1982.

Rojas M., Álvaro, "Campesinado y mercado de alimentos en un modelo de economía abierta", en CEPAL, La agricultura campesina y el mercado de alimentos: la dependencia externa y sus efectos en una economía abierta, Santiago de Chile, Naciones Unidas, 1984, pp. 97-201.

Schejtman, Alexander, "Economía campesina: lógica interna, articulación y persistencia", en Revista de la CEPAL núm. 11, Santiago de Chile, Naciones Unidas, agosto de 1980 .

Warman, Arturo, $Y$ venimos a contradecir. Los campesinos de Morelos y el Estado nacional, México, INAH-La Casa Chata, 1976.

\section{Desarrrollo}

